\title{
The Influencing Factors and Suggestions about College Students' Lack of Learning Motivation
}

\author{
Tian-lin CHEN* \\ Psychological Counseling Center \\ Jiangxi University of Traditional Chinese Medicine \\ Nanchang, Jiangxi, China \\ 88110440@qq.com
}

\author{
Zhen LI \\ Graduate School \\ Jiangxi University of Traditional Chinese Medicine \\ Nanchang, Jiangxi, China
}

\author{
Lan LUO \\ School of Humanities \\ Jiangxi University of Traditional Chinese Medicine \\ Nanchang, Jiangxi, China
}

\begin{abstract}
Objective to investigate the influencing factors of College Students' lack of learning motivation. Methods: A comprehensive study of the past five years was conducted to analyze and integrate the literature. Results: There were some subjective and objective influencing factors in the lack of learning motivation. Conclusion: In view of the subjective and objective factors influencing the lack of learning motivation, it is suggested that we should change our learning plan, cultivate interest in learning, improve teaching methods and create a learning atmosphere.
\end{abstract}

Keywords-college students, lack of learning motivation, influencing factors, Suggestions.

\section{INTRODUCTION}

For college students, learning is the dominant activity and the main task during their study. Learning motivation plays an important role in their learning behavior and effectiveness. If the motivation is adequate, they will have good learning enthusiasm, which will lead to sustained learning behavior However, the lack of motivation for college students is becoming more and more common in Colleges and universities. The findings of recent years show that quite a few problems exist in students' lack of learning motivation, especially for non key university students[1]. Students truancy phenomenon caused because of the insufficiency of learning motivation, the fail exams because of the problem of skipping classes, infatuation with network problems have severely affected the current education of the improvement of teaching quality in colleges and universities as well as the improvement of talent training level Therefore, it is imperative to adopt a reasonable way to stimulate the motivation of College students.

Project supported by the subject of science and technology in Jiangxi province (GJJ150878)

Corresponding Author; Tian-lin CHEN

\section{THE EXPRESSION OF LACK OF LEARNING MOTIVATION IN COLLEGE STUDENTS}

\section{A. No Definite Learning Goal and Plan}

Some college students have no clear learning goals and plans, neither long-term goal nor goal in the near future. During the college, they have no idea about what to learn or how to learn every year. what requirements they should get are rarely considered, either. Moreover, learning behaviors tend to show conformity and dependence. In the period of the University, the incidence of students' conformity behavior is more than $80 \%$. They pay attention to groups, especially the roommates who live with each other, and pay attention to the students. If a student is able to identify himself with his classmates, he has a sense of belonging and thus increases his self-confidence. We often see that some bedrooms strive for TEM-4 or TEM6, or are interested in student work and community public welfare activities, some have submitted their applications for membership. And some bedroom have the phenomenon of make-up exams, rehabilitation or truancy. truancy is becoming a frequent phenomenon

\section{B. Lazy and Attention Scattered}

The main performance of laziness is usually unwilling to read and use their brains. They are lazy on study, fear of hardships, and often make excuses for their own laziness. The main distraction of inattention is unable to concentrate on reading and thinking, their interests are easy to transfer and satisfied with a smattering of knowledge.

\section{Bad style of Study, Tired of Learning, Escape Learning}

The student attendance rate is not high, they do everything possible to skip school; they does not listen or take notes in the class, they take learning as a chore, do not do the exercises, copy homework after class. They prefer to put a lot of time and energy in chatting, playing games, playing cards and other extracurricular activities and abandoned their studies. College students cheating in the exam is also a widespread 
phenomenon, the construction of good style of study and examination will be a long lasting work.

\section{No Sense of Achievement}

Some college students' curiosity and ambition are seriously insufficient, they have few responsibility or pressure or sense of urgency, they neither envy those have good grades, nor feel humiliated for their own poor learning, they are not interested in all kinds of incentives of schools and not afraid of all kinds of punishment measures .

\section{E. No appropriate learning method}

Nowadays, college students are lack of suitable learning methods and have difficulty in listening to lectures. Some students lack of comprehensive summary of thinking ability, they can't adapt to college learning way ,such as listening, remember, while thinking of the knowledge, the progress is quickly that they can't grasp the points. The lack of proper learning methods has made them not form a good study habit. The noise, the interference of other activities such as environmental chaos or too comfortable will have bad effect on concentration,

\section{FACtors AfFecting THE LACK OF LEARNING Motivation of College Students}

The occurrence of anything is the result of the subjective and objective factors. The learning motivation of college students has no exception. In general, college students lack motivation and subjective and objective factors.

\section{A. Subjective Factors of Lack of Learning Motivation of College Students}

\section{1) Learning target missing}

Due to China's college entrance examination system, the learning motivation of students in the middle school is external, that is admitted to the University is their own efforts to learn.This is actually the society, parents' expectations, rather than their internal needs, therefore, at the beginning of high school, their learning motivation is not yet fully established. Once the goal of getting into college has been achieved, about what will be done and how to do it in the future, many college students are at a loss. As for under the new environment, updating their learning method is not considered by many students. They do not know how to determine the learning plan, which leads their university life in the days to a blind mixed state.

\section{2) Lack of professional interest}

Many students is not interested in their major subjects while entering college. Because many students do not understand the specialty, just follow the wishes of their parents. Or by the score limit, they are transferred to other subjects and lose ideal professional qualifications. Because of unwillingness, they get bored on their study. At the same time, due to factors such as employment, some students may learn social influence and professional employment prospects lack of confidence. When facing this situation, they do not turn pressure into motivation, but blame others, and have no desire to learn.

\section{3) Poor self-control}

Because the way of university learning is different from that of high school, college students often don't know what to do when no one is in command. In addition to lower grades is consist of general public courses, basic courses. The learning content is so obsolete, boring and heavy that need them to devote more time and energy to these classes. Some of the students can not cope with the university learning rhythm. Therefore, for those who are poor self-control, easily influenced by others, they tend to choose naturally or half unconsciously Internet, amusement and other ways to escape. Eventually because of long time escape, they completely lose interests in learning, even get bored or hate it.

\section{4) Employment pressure}

College enrollment and the recent financial crisis worsen the employment pressure of college students. In the employment process of college students, there are still unfair competitions, such as the back door, looking highly of education but not ability, gender discrimination. They seriously dampened the enthusiasm of students learning. As a result, many college students tend to be uninterested in, or even tired of, or resisting.

\section{5) Lack of self-confidence}

After the college entrance examination, some students who entered the university had a relaxed attitude, so the performance get down all the way, and the formation of a great contrast with the high school stage, lack of selfconfidence, they can not stand these temporarily because of a failure of the test, examination. At the same time, there are some students have the feeling of inferiority because of family economic difficulties. They often take such feelings of inferiority into all kinds of learning, and then influence the academic confidence.

\section{B. Objective Factors of Lack of Learning Motivation}

\section{1) Family factors}

Family environment has a direct impact on the growth of a person. Curiosity, self-esteem, independence, self-control, and attitudes toward setbacks and difficulties are all related to the family environment. Recognition in family education is very important for individuals to stimulate their learning motivation. According to the survey results, a good student, the appreciation rate of his or her family education reached $37.94 \%$, while criticized one reach only $0.49 \%$. However, the poor performance of the class $\mathrm{C}$ students, have a low rate of only $8.86 \%$, often criticized by the $5.06 \%$. Good students receive more praise than criticism, and poor ones are more critical than praise[2]. In real life, our students have positive incentive in family education is insufficient, many parents are often concerned about the economic situation of college students and the result is good or bad, once see their children's achievement is not ideal, what they do is often not encourage but often accuse.

\section{2) Social factors}

As the enrollment expansion system of universities in our country, the number of college graduates in our country has risen sharply, and the employment pressure of college graduates is becoming larger and larger. Because of 
oversupply, coupled with the students often have grandiose aims but puny abilities, which makes some students feel difficult when looking for a job. At the same time, even if some students find jobs, they may also feel unsatisfied because of professional counterparts, poor wages and dissatisfaction. Meanwhile, because China's current social competition system is not perfect, the employment competition tends to affect the social relations. So severe employment situation has seriously affected the enthusiasm of learning a part of current college students, let them have the feeling of learning is useless, and this negative emotion can affect learning motivation.

\section{3) School education factors}

There is a big difference between college and middle school learning styles. The initiative of university teaching emphasizes students' consciousness, students are required to have independent thinking and research learning. But for college students, due to the high school education supervised learning mode for a long time, in the face of time free of confusion, they do not know how to learn, what to learn, and waste a lot of time. At the same time, the current examination in various universities is loose, and perhaps students step into an illusion that learning without effort, as long as the end of the time, they think if they spend time focusing on review, they can even get high marks. This way of examination can not accurately reflect the professional level of students, thus affecting the enthusiasm of College students.

\section{SUGgestions FOR IMPROVING COLLEGE STUDENTS' LEARNING MOTIVATION}

\section{A. To strengthen College Students' Learning and Life planning Guidance}

Lack of motivation for college students, the most important subjective factor is the lack of goals. Therefore, we should strengthen the planning guidance when the university students enter the school, and let them plan their study, life and other factors according to their own actual conditions and the University environment. Scientific life and learning planning is conducive to the formation of a correct view of learning, and enhance learning motivation.

\section{B. Cultivate Interest in Learning}

Learning interest is the most basic element to stimulate learning motivation in the course of learning. Learning interest can effectively motivate students, so that they can give full play to their potential, and thus improve learning efficiency, [3]. For the cultivation of interest, we must first cultivate interest in professional learning. School can do it through teacher guidance, social practice, academic forums and other ways to help students understand the prospects, training objectives, teaching content arrangement. It will stimulate students to love their majors and yearn for the future life. At the same time, the school should strengthen the novelty of the teaching content and attract the students' attention according to the changing social situation; and arouse the students' enthusiasm by using flexible teaching methods.

\section{To Enhance the Internal Motivation of Learning}

In a sense, as a powerful spiritual force, it can stimulate the students' sense of crisis and sense of responsibility, and thus inspire them to struggle. To increase the students' sense of hardship, we can strengthen the education of the national history of college students to enhance their sense of urgency. National history education not only can make college students better understand our country's long history, but more importantly, it can sum up historical experience and lessons. Especially in the modern history of our country, as a humiliating history of our nation, it can stimulate college students' National indignation and patriotic enthusiasm, so as to cultivate their sense of urgency and enhance their learning motivation. At the same time, we should also attach importance to the education of national conditions and strengthen the education of the students' sense of urgency. The education of national conditions not only helps students understand the line, principles and policies of the party and the state, but also enables students to compare the difficulties faced by the national development and the gap between the world and the world so as to stimulate the motivation for learning.

\section{Scientific Teaching Management}

As the University, to continue to reform the teaching mode and plan should adjust the training scheme of each school, professional, and social ties and increase all kinds of elective courses; at the same time, university also should pay attention to the training of students' personality and ability promotion. It should be based on the needs of social development, vigorously strengthen quality education, training of teaching methods and practice ability from all kinds of courses, to mobilize students' learning initiative and enthusiasm. What's more, we should pay attention to the teaching mode of "taking students as the main body and leading by teachers". To stimulate students' awareness of active learning, let students become the real classroom "leading role", so as to arouse the initiative and creativity of students, to enable students to "learn to learn, learn to discover, learn to do, learn to survive (problem solving)".

\section{E. Strengthen the Bedroom Culture Construction, Create a Good learning Atmosphere}

As an important place for college students to live in, dormitory is an important platform for students to get a sense of belonging. Most of the students' real life and psychological activities are mainly based on the groups in the community, which make the members' consciousness, behavior and behavior interact with each other. Dormitory environment has a great influence on the learning motivation of college students. The relationship between students plays an important role in learning and life [4]. Dormitory environment is poor, it must affect the whole dormitory learning motivation. A good dormitory culture is conducive to the formation of a good style of study, which can stimulate students' interest in learning and improve their learning motivation. To form a good dormitory culture, first of all, in the management of the students, each student should be understood ; secondly, in the layout of the bedroom, take the collocation into account in each dormitory 
to make sure it is reasonable; thirdly, in the management of students, guide students' spontaneous factors so that they form a healthy and positive dormitory culture. In addition, we should improve the school's hardware and software conditions to create a good environment for college students and improve their learning motivation. Colleges and universities should take all kinds of incentives to create a dormitory style of study, so as to promote the students' sense of competition and reference, and effectively improve the enthusiasm of students learning initiative.

\section{CONCLUSION}

In short, in recent years, the phenomenon of lack of motivation for college students in our country has become more and more serious. This phenomenon will directly affect the quality of education in Colleges and universities and the level of personnel training. To stimulate and enhance motivation in learning of college students in our country, the main parts of the society, schools and teachers should unite together to help college students to establish reasonable learning goals, clear positioning of their occupation. Only by this, can students achieve the purpose of reinforcement learning interest, improve the learning enthusiasm. And we can ensure the teaching quality of Chinese higher education, which contributes the construction of socialist modernization qualified builders.

\section{REFERENCES}

[1] Zhang Ming, Liu Chunling. Analysis of the driving force of college students [J]. Heilongjiang science and technology information, 2010, (10) .(In Chinese)

[2] Chen Yunpu, Zhang Li. The impact of College Students' change of learning concept on learning dynamics [J]. social science and technology, 2009, (11) . (In Chinese)

[3] Xu Peiqing. Learning motivation of college students: Problems and Countermeasures to enhance $[\mathrm{J}]$. education information, 2010, (5). (In Chinese)

[4] Zhu Zhu, Wang Peng, Lin Lin. strengthen the construction of dormitory culture and improve the students' learning motivation. [J], Journal of Harbin Financial college, 2009,22 (4) .(In Chinese) 